\title{
Egalitarianism and Sexual Prejudice: the Role of Ingroup Distinctiveness Motives
}

\author{
Juan Manuel Falomir-Pichastor, Jacques Berent, Gabriel Mugny and Klea Faniko \\ University of Geneva (Switzerland)
}

\begin{abstract}
The present research examined the hypothesis that heterosexual men's motivation to differentiate their ingroup from gay men moderates the link between egalitarianism and sexual prejudice. In two experiments conducted in Switzerland $(N=74)$ and Ecuador $(N=104)$, we assessed heterosexual men's endorsement of egalitarian values and experimentally manipulated scientific evidence supporting or refuting the existence of biological differences between heterosexual and gay men (the biological theory). The main dependent variable was attitude towards homosexuality. As predicted, the interaction between egalitarianism and the biological theory was significant in both experiments, $t(67)=3.18, p=.002, \eta_{\mathrm{p}}{ }^{2}=.13$, and $t(100)=2.26, p=.026, \eta_{\mathrm{p}}{ }^{2}=.04$, respectively. Egalitarianism increased positive attitudes towards homosexuality only when science supported the existence of biological differences between heterosexual and gay men. We discuss the relevance of this finding to intergroup relations.
\end{abstract}

Received 17 July 2014; Revised 6 January 2015; Accepted 9 January 2015

Keywords: egalitarianism, ingroup distinctiveness, intergroup differences, biological determinism, sexual prejudice.

People in Western societies increasingly endorse egalitarian values (Davidov, Schmidt, \& Schwartz, 2008), yet prejudice towards specific social groups (such as sexual minorities) still prevails (Crandall, Eshleman, \& O'Brien, 2002). This apparent paradox suggests that some groups fall outside the sphere into which egalitarian values are applied, and that prejudice towards these groups may therefore seem tolerable or even justified. In the present research we addressed this issue by focusing on heterosexual men's motivation to distinguish their ingroup from that of gay men. More specifically we investigated whether such ingroup distinctiveness motive moderates the link between endorsement of egalitarian values and positive attitudes towards homosexuality.

\section{Egalitarianism and intergroup prejudice}

Values are general beliefs that are central to the selfconcept, and that influence the way individuals construe and evaluate situations by informing them about the desirability of various goals and behaviors (Feather, 2005; Rokeach, 1973; Schwartz, 1992). Accordingly, egalitarian values inform individuals that everybody, independently of their group membership, should be treated equally, and that prejudice, group-based inequalities,

Correspondence concerning this article should be addressed to Juan M. Falomir-Pichastor. University of Geneva. Social Psychology (FPSE). 40 Bd. du Pont-d'Arve. CH-1205. Geneva, Switzerland.

E-mail: Juan.Falomir@unige.ch

This material is based upon work supported by the Swiss National Science Foundation (Grant number: 100011-100283). We are grateful to Suzanne Noëll, Marie-Françoise Pitteloud and Maria Elena Sandoval for their help in collecting data. and discrimination are unacceptable. Research has consistently shown that the extent to which people endorse egalitarian values (i.e., egalitarianism) is related to more tolerant and less prejudiced attitudes towards social minorities (e.g., Biernat \& Vescio, 1996; Feather \& McKee, 2008). However, egalitarian people do not always display non-prejudiced attitudes, and the level of prejudice they display is also sensitive to the social context. For example, the link between egalitarianism and non-prejudiced attitudes appears to be weakened in competitive intergroup contexts (e.g., Bahns \& Crandall, 2013; Biernat \& Vescio, 1996), because prejudice towards social minorities that threaten the ingroup's power and status appears to be justified (e.g., Crandall \& Eshleman, 2003).

The present research was designed to examine the hypothesis that the link between egalitarianism and non-prejudiced attitudes is not straightforward. In fact, we argue that equality is a double-edged sword. On the one hand, and as noted above, it would be logical to assume that valuing intergroup equality would result in more tolerant and less prejudiced intergroup attitudes. On the other hand, equality ultimately restricts intergroup differentiation and may therefore threaten ingroup distinctiveness needs (Jetten \& Spears, 2003: Tajfel \& Turner, 1986). As a consequence, and somewhat paradoxically, we contend that endorsing egalitarian values will not contribute to reducing prejudice in people who are strongly motivated to maintain intergroup differences.

Social identity theory (Tajfel \& Turner, 1986) provides the basis for this hypothesis. This theory assumes that individuals derive their self-concept and self-esteem 
from their perceived membership in relevant social groups. Thus, individuals are motivated to belong to groups that provide them with distinct and positive social identities, and to positively differentiate their ingroup from relevant outgroups when the ingroup's distinctiveness is threatened. This reactive distinctiveness process is moderated by both dispositional and situational factors: reactive distinctiveness is a more common response among people who largely derive their self-concept from their group membership, and in contexts that activate (rather than fulfill) the distinctiveness need. Indeed, past research has consistently shown that perceived ingroup-outgroup similarity can threaten ingroup distinctiveness which, in turn, increases intergroup differentiation efforts (in particular among highly identified group members; Jetten \& Spears, 2003; see also Brewer, 1991).

Even though egalitarianism is expected to increase concerns about intergroup equality and intergroup similarity, we contend here that the endorsement of egalitarian values can also threaten ingroup distinctiveness needs, and therefore activate such a reactive distinctiveness process. This general process should appear specifically when dispositional or situational factors activate strong distinctiveness needs. Research on intergroup relations provides indirect support for this hypothesis. Indeed, scholars have consistently shown that the categorization process often leads to prejudice and that de-emphasizing intergroup categorization (i.e., claiming that all individuals are equal, no matter the group they belong to) can reduce prejudice (e.g., Gaertner, Mann, Murrell, \& Dovidio, 1989). However, intergroup categorization also accomplishes important identity functions (Tajfel \& Turner, 1986), and resolving social conflicts without dismantling group boundaries and identities is often a more successful strategy (Hornsey \& Hogg, 2000; Wolsko, Park, Judd, \& Wittenbrink, 2000). As social equality implies an increased perception of similarity between all individuals and groups (like a colorblind ideology), this research suggests that egalitarianism can be paradoxically linked to intergroup differentiation efforts and to increased prejudice.

Research on the negative effects of equality in the case of groups from which people want to distance themselves provides additional support for this hypothesis. For example, nationals with negative attitudes towards immigrants consider nationality to come with some privileges and obligations that differentiate nationals from immigrants (e.g., Mugny, Sanchez-Mazas, Roux, \& Pérez, 1991). Accordingly, individuals with moderate antioutgroup attitudes polarize their negative attitudes when they are forced to treat the ingroup and the outgroup equally, as compared to when they can treat these groups unequally (Sanchez-Mazas, Roux, \& Mugny, 1994).
More relevant for the present purpose, individuals with a high propensity to feel ingroup distinctiveness threat strive to maintain intergroup differences, particularly when primed with egalitarian norms (Falomir-Pichastor \& Hegarty, 2014; Gabarrot, FalomirPichastor, \& Mugny, 2009). Again, this research suggests that either egalitarian people or people in egalitarian normative contexts may consider the equal treatment of groups from which they want to differentiate as a threat. Under such circumstances, their egalitarian values should no longer predict (or predict to a lesser extent) a positive attitude towards these outgroups.

Nevertheless, egalitarianism should not necessarily be considered as a systematic threat to ingroup distinctiveness. It should only constitute a threat to ingroup distinctiveness among people who are dispositionally or situationally motivated to maintain or restore clear-cut intergroup boundaries. As a consequence, among these people, egalitarianism should lead to reduced prejudice only if ingroup distinctiveness needs are satisfied by other means. The present studies tested this hypothesis with respect to sexual prejudice among heterosexual men, as research has shown that heterosexual men are particularly motivated to psychologically differentiate themselves from gay men. Accordingly, heterosexual men's attitudes towards homosexuality provide an ideal context to test our main hypothesis.

\section{Masculinity and ingroup distinctiveness}

Gender differences appear to be one of the strongest and most reliable predictors of sexual prejudice: compared with heterosexual women, heterosexual men show more negative attitudes towards homosexuality, particularly towards gay men (e.g., Whitley, 2001). Men's sexual prejudice is often explained in terms of gender socialization processes that traditionally convey the notion that masculinity is defined as being in opposition to femininity and to homosexuality (such oppositions do not seem to be as strong regarding the definition of femininity; e.g., Bem, 1993; Herek, 1986). Consequently, sexual prejudice would allow heterosexual men to affirm their masculinity by showing that they are neither feminine nor gay. This contention is supported by research showing that men's sexual prejudice is related to greater endorsement of the antifemininity norm of masculinity, which represents the belief that men should avoid stereotypically feminine behaviors (e.g., Keiller, 2010). Furthermore, men's sexual prejudice is directed against feminine (rather than masculine) gays as a reactive response to specific threats to their own masculinity (Glick, Gangl, Gibb, Klumpner, \& Weinberg, 2007). 
Another consequence of gender socialization processes is that heterosexual men are particularly motivated to psychologically distance themselves from gay men (Theodore \& Basow, 2000). Indeed, heterosexual men who are concerned about being misclassified as gay feel a degree of discomfort that is alleviated when they publicly claim their heterosexuality (Bosson, Prewitt-Freilino, \& Taylor, 2005). Words such as 'fag' and 'queer' are often perceived as the worst insults that can be directed at heterosexual men (Burn, 2000), and male heterosexuals frequently distance themselves from gay men after being exposed to homophobic labels (Carnaghi, Maass, \& Fasoli, 2011). Correlational research also suggests that sexual prejudice is related to men's perception of dissimilarity between themselves and gay men (Herek, 1986; Talley \& Bettencourt, 2008). Moreover, the links between sexual prejudice and the endorsement of traditional gender roles on the one hand (Falomir-Pichastor, Martinez, \& Paterna, 2010), and between sexual prejudice and gender self-esteem on the other (Falomir-Pichastor \& Mugny, 2009), are stronger for men who perceive greater dissimilarities between themselves and gay men.

Finally, research also showed that heterosexual men are motivated to psychologically distance themselves from gay men at the group level (i.e., intergroup differentiation), notably through increased beliefs in biological differences between gay and heterosexual men. Indeed, men's sexual prejudice is related to an increased perception of biological differences between heterosexual men and gay men, specifically under egalitarian norms (Falomir-Pichastor \& Hegarty, 2014). A similar effect has been reported for heterosexual men with narrow prototypes for masculinity that exclude gay men (Falomir-Pichastor \& Hegarty, 2014). In line with these findings, heterosexual men tend to perceive more similarities between themselves and gay men (and to display less sexual prejudice) when they are provided with scientific evidence supporting the existence of biological differences between heterosexual and gay men (Falomir-Pichastor \& Mugny, 2009). Whereas past research showed that beliefs in the biological basis of sexual orientation are related to less prejudice because they increase the perception that homosexuality is beyond individual control and responsibility (e.g., Haider-Markel \& Joslyn, 2008; Hegarty, 2002), these findings might suggest that the biological theory of sexuality also accomplishes the defensive function of maintaining clear-cut intergroup boundaries.

\section{The present research}

According to this body of research, masculinity is intrinsically defined as based on heterosexuality and in opposition to femininity and, in order to maintain a distinctive gender identity, heterosexual men appear to be particularly motivated to differentiate their ingroup from gay men. Therefore, we hypothesized that egalitarianism might pose a threat to heterosexual men's motivation to distinguish from homosexuals, and that egalitarianism will be related to reduced sexual prejudice only if heterosexual men's ingroup distinctiveness needs are satisfied by other means (through, for example, a perception of biological differences at the intergroup level).

We tested this hypothesis via two studies. In both studies we initially assessed the importance that heterosexual men attribute to social equality in general and then experimentally manipulated the existence of biological differences (or similarities) between heterosexual and gay men. Study 1 included a control condition in which no information about the biological determinism of sexuality was provided to the participants. We postulated that egalitarianism would predict positive attitudes towards homosexuality in the biologically different condition (i.e., when ingroup distinctiveness is granted), but not in the biologically similar condition (i.e., when ingroup distinctiveness is threatened) or in the control condition (as biological similarity can be considered a default perception; Falomir-Pichastor \& Mugny, 2009). Given that past research often related biological determinism to immutability beliefs rather than distinctiveness beliefs (Haslam \& Levy, 2006; Hegarty, 2002), Study 2 included a measure of perceived control over sexual orientation in order to rule out the possibility that the biological differences induction moderates the effect of egalitarianism on sexual prejudice because of the increased perception that sexual orientation is not under individual control.

Finally, we should specify that these studies were conducted in Ecuador and Switzerland. Past research on masculinity affirmation and sexual prejudice used samples from North American and European countries and, to our knowledge, no previous study examined reactive distinctiveness processes across different countries. Thus, this procedure offered an opportunity to determine whether the processes under study vary across samples from two different countries. Despite that masculinity is socially constructed, and that the meaning attached to it can vary across cultures and historical contexts (Herek, 1986), there are also reasons to think that the construction of masculinity as heterosexual is quite common at least across European and American societies. Furthermore, masculinity scores as assessed in terms of traditional views of gender roles are relatively high both in Switzerland and Ecuador (Hofstede, Hofstede, \& Minkov, 2010). Therefore, we assumed that men's motivation to psychologically distance themselves from gay men can be found in 
both Ecuador and Switzerland samples, and we expected to find a similar pattern of findings in the two studies.

\section{Method}

\section{Participants and procedure}

Participants were recruited on the campuses of a Swiss University (Study 1, 85 men) and of an Ecuadorian University (Study 2, 139 men). The final samples included 74 participants (Study 1; age: $M=23.93, S D=5.97$ ) and 104 participants (Study 2; age: $M=20.10, S D=1.78$ ) selected on the basis of their self-reported heterosexuality (see below). Unless otherwise indicated, responses were provided on 7-point Likert-type scales ranging from 1 ('not at all' or 'absolutely disagree') to 7 ('absolutely' or 'absolutely

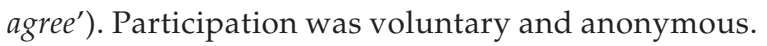
After they had completed the questionnaire, participants were thanked and debriefed. More concretely, participants were informed about the goal and methods of the research and about the existing evidence on potential biological differences between heterosexual and homosexual men, and were finally sensitized to the difficulty of unequivocally claiming that sexual orientation is biologically determined.

\section{Materials}

\section{Endorsement of egalitarian values}

Participants' degree of egalitarianism was assessed in Study 1 with a single question focusing on discrimination against social minorities ('How important is it for you not to discriminate against social minorities?'; $M=6.58$, $S D=0.91$ ) and, in Study 2, with 3 items focusing on the importance of equality in general ('Equality between all individuals is fundamental in my personal relationships', 'Not discriminating is a very important principle to $\mathrm{me}^{\prime}$, and 'Creating a society that functions well is mainly dependent on treating all individuals according to the principle of equality'; $\alpha=.79, M=5.87, S D=1.22)$. Note that these measures relate to intergroup equality in general rather than to a specific (sexual) minority group.

\section{Biological theory of sexuality}

The perception of intergroup differences at the biological level was manipulated as in Falomir-Pichastor and Mugny (2009, Study 5). Participants were presented with purported findings of scientific research comparing gay and heterosexual men in terms of genetic structure, mother's androgen rate during pregnancy, and physiology (i.e., the weight of the part of the hypothalamus responsible for sexual orientation). In the biologically different condition, the results stressed the existence of clear biological differences between gay men and heterosexual men, and indicated that male homosexuality is biologically determined. In the biologically similar condition, the results emphasized the lack of scientific evidence for any biological difference between gay men and heterosexual men, and indicated that male homosexuality is not biologically determined. In addition, Study 1 included a control condition in which the participants were not given any information about the biological basis of sexual orientation.

\section{Dependent variables}

In order to check our experimental inductions, one item assessed participants' endorsement of the biological theory of sexuality ('Male homosexuality is biologically determined'; Study 1: $M=2.58, S D=1.35$; Study 2: $M=3.47, S D=2.09$ ). Positive attitudes towards homosexuality (our main dependent variable) were assessed using Falomir-Pichastor and Mugny's (2009) 25-item scale. Items included 'Homosexuality is contrary to family values' (reversed score), 'I feel empathy for homosexuals', 'Homosexual couples should have the right to adopt children', or 'I would not mind sharing an apartment with a homosexual'. Scores were averaged to form a measure of attitude towards homosexuality on which higher scores indicated more positive attitudes (Study 1: $M=4.46$, $S D=0.78, \alpha=.89$; Study 2: $M=3.48, S D=0.99, \alpha=.90$ ). Overall, egalitarianism was not correlated with attitude towards homosexuality (Study 1: $r=.06, p=.60$; Study 2: $r=.16, p=.11$ ). In Study 2, two items additionally assessed participants' perception that sexual orientation is under individual control: 'Homosexual men voluntarily decide their sexual orientation', and 'Homosexual men are responsible for their sexual orientation' $^{\prime}(r=.44, p<.001 ; M=5.17, S D=1.45)$. Attitude towards homosexuality was not correlated with the perception that sexual orientation is under individual control $(r=-.11, p=.24)$.

\section{Demographics}

Finally, participants answered several demographic questions, including three questions about their sexual orientation. They were asked to define themselves as either 'heterosexual', 'bisexual', or 'homosexual', to indicate whether they have had sexual intercourse with a person of the same sex ('yes' vs. 'no'), and whether they ever felt attracted to people of the same sex (on a scale ranging from $1=$ never, to $7=$ frequently). Participants were only included in the study if they defined themselves as heterosexuals, reported that they had not previously had sexual relationships with same-sex partners, and scored below the middle point of the scale in the attraction question (see Falomir \& Mugny, 2009). 


\section{Results}

\section{Study 1}

Given that this study included a control condition, we calculated two orthogonal contrasts. The first contrast compared the biologically different condition $(-2)$ to the biologically similar $(+1)$ and control $(+1)$ conditions, whereas the second contrast compared these latter two conditions $(0,-1,+1$, respectively). We regressed the dependent variables on participants' endorsement of egalitarianism (standardized scores), the two contrasts, and the two interactions between egalitarianism and each contrast.

\section{Manipulation check}

One participant did not respond to the manipulation check item. Overall, the statistical model explained a significant part of the variance, $R^{2}=.16, F(5,66)=2.51$, $p=.038$. Results showed that the first contrast was significant, $t(66)=2.35, p=.021$, with belief in the biological theory being stronger in participants in the biologically different condition $(M=3.05, S D=1.21)$ than in the biologically similar $(M=2.22, S D=1.25)$ and control $(M=2.30, S D=1.59)$ conditions. The second contrast, $t(66)=0.50, p=.61$, and the main effect of norm endorsement, $t(66)=1.46, p=.14$, were not significant. The interaction including the second contrast was not significant, $t(66)=1.23, p=.22$, but the interaction including the first contrast was, $t(66)=2.29$, $p=.025$. For high egalitarians $(+1 S D)$, endorsement of the biological theory was higher in the biologically different condition $(M=3.31)$ than it was in the biologically similar $(M=1.96)$ and control conditions $(M=1.50)$, $t(66)=3.38, p=.001$. This contrast was not significant for low egalitarians $(-1 S D), t(66)=0.20, p=.83$. Given that this interaction effect was not reproduced in Study 2 we do not discuss it further here.

\section{Positive attitude towards homosexuality}

Overall, the statistical model explained a significant proportion of the variance, $R^{2}=.21, F(5,67)=3.72$, $p=.005$. The regression analysis showed that only the first contrast by egalitarianism interaction effect was significant, $t(67)=3.18, p=.002, \eta_{\mathrm{p}}{ }^{2}=.13$ (see Figure 1$) .{ }^{1}$ Slope analyses showed that egalitarianism increased

\footnotetext{
${ }^{1}$ In order to provide a direct comparison between the two experimental conditions, as in Study 2, a similar regression analysis was computed using two different contrasts. The first contrast opposed the control condition (coded as +2 ) and the two experimental conditions (both coded as -1), and the second contrast opposed the biologically different and biologically similar conditions (coded as -1 and +1 , respectively; the control condition was coded as 0 ). This analysis only revealed a significant interaction effect between egalitarianism and the second contrast, $t(67)=3.78, p<.001, \eta_{\mathrm{p}}^{2}=.17$.
}

positive attitudes towards homosexuality in the biologically different condition $(B=.45), t(67)=3.32$, $p=.001$, but not in the control and biologically similar conditions $(B=-.19), t(67)=1.28, p=.20$. Moreover, the first contrast was not significant for low egalitarians $(-1 S D), t(67)=1.47, p=.14$, but was significant for high egalitarians $(+1 S D), t(67)=3.46, p=.001$, with attitudes being more positive in the biologically different condition than in the biologically similar and control conditions.

\section{Study 2}

We regressed the dependent variables on endorsement of egalitarianism (standardized scores), the biological theory manipulation (coded -1 for biologically different, and +1 for biologically similar), and their interaction term.

\section{Manipulation check}

The regression analysis, $R^{2}=.09, F(3,100)=3.36, p=.022$, revealed a significant effect of the biological theory manipulation, $t(100)=2.85, p=.005$, with participants believing more strongly that sexual orientation is biologically determined in the biologically differences condition $(M=4.06, S D=1.89)$ than in the biological similarities condition $(M=2.92, S D=2.13)$. The main effect of egalitarianism and the interaction effects with both independent variables were not significant, $t(100)<1.22, p>.22$.

\section{Positive attitude toward homosexuality}

The regression analysis, $R^{2}=.10, F(3,100)=3.52, p=.018$, revealed a marginally significant main effect of egalitarianism $(B=.17), t(100)=1.85, p=.067, \eta_{\mathrm{p}}^{2}=.03$, with higher egalitarian values tending to increase positive attitudes toward homosexuality. The effect of biological theory was not significant, $t(100)=1.52$, $p=.13, \eta_{\mathrm{p}}^{2}=.02$, but the predicted interaction was, $t(100)=2.26, p=.026, \eta_{\mathrm{p}}^{2}=.04$ (see Figure 1). Egalitarianism increased positive attitudes towards homosexuality in the biologically different condition $(B=.39), t(100)=2.85, p=.005$, but not in the biologically similar condition $(B=-.04), t(100)=0.30, p=.66$. Moreover, no significant differences were observed for low egalitarians $(-1 S D), t(100)=0.54, p=.59$, but the attitudes of high egalitarians were more positive in the biologically different condition than in the biologically similar condition $(+1 S D), t(100)=2.68, p=.009$.

\section{Perception of individual control}

Regarding the perception that sexual orientation is under individual control, $R^{2}=.09, F(3,100)=3.59$, $p=.016$, the analysis revealed a significant main effect 


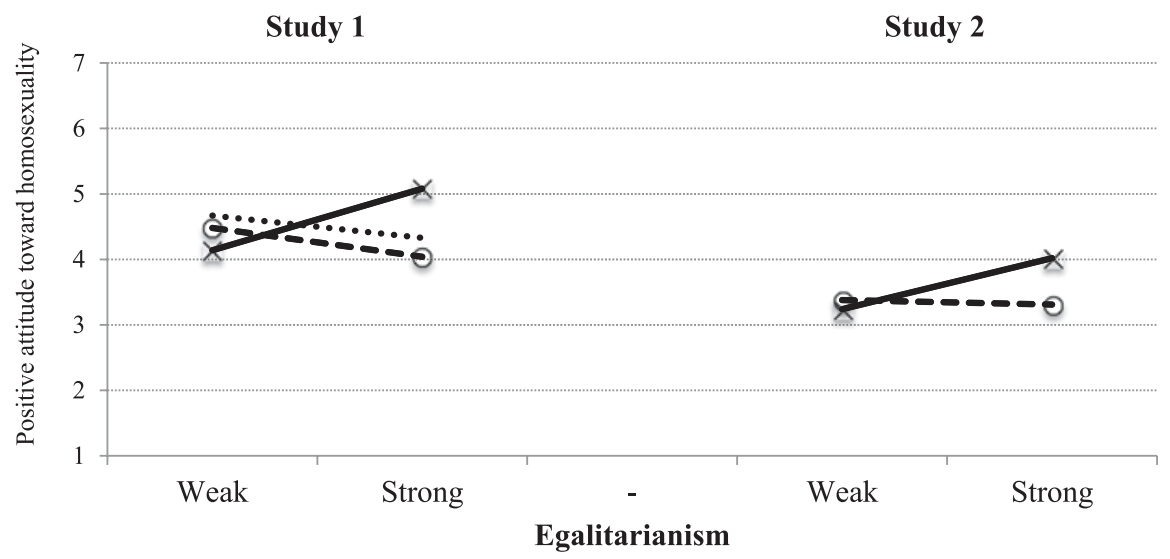

$\leftarrow$ Biologically different $\quad-\Theta-$ Biologically similar $\quad \cdots .$. Control

Figure 1. Predicted Values for Heterosexual Men's Positive Attitude Toward Homosexuality as a Function of Endorsed Egalitarianism (-/+1SD) and Biological Theory Condition.

of egalitarianism $(B=.37), t(100)=2.71, p=.008, \eta_{\mathrm{p}}^{2}=.06$, with higher egalitarian values increasing the perception that sexual orientation is under individual control. However, the main effect of the biological theory manipulation, $t(100)=1.38, p=.17$, and the interaction effect, $t(100)=1.12, p=.26$, were not significant. Finally, the interaction between egalitarianism and biological theory on attitudes toward homosexuality observed previously remained significant when perception of individual control was additionally introduced in the regression analysis, $t(99)=2.11, p=.037, \eta_{\mathrm{p}}{ }^{2}=.04$.

\section{Discussion}

We conducted two studies to test the hypothesis that perceived intergroup differences at the biological level moderate the link between heterosexual men's endorsement of egalitarian values and the expression of sexual prejudice. The results consistently showed that endorsement of egalitarian values was related to more positive attitudes towards homosexuality, but specifically when science supported the existence of biological differences between heterosexual and gay men. Indeed, egalitarianism was no longer related to sexual prejudice when science was thought to refute such biological differences. The control condition included in Study 1 showed the same pattern of findings observed in the biological similarities condition, suggesting that it was the biological differences condition that allowed the influence of egalitarian values on attitudes rather than the biological similarities condition that inhibited such a link. This result is consistent with the fact that beliefs about biological determinism were identical in the biologically similar and the control conditions, as well as with the findings reported by Falomir-Pichastor and Mugny
(2009; Study 5). Finally, we obtained comparable results using different measures of egalitarianism and two samples of heterosexual men recruited in two different countries (Switzerland and Ecuador).

These findings contribute to at least three research domains. First, they add to studies on the link between ideologies and prejudice by showing that threatening intergroup contexts moderate the link between ideologies and intergroup attitudes (e.g., Bahns \& Crandall, 2013; Correll, Park, \& Smith, 2008). Specifically, the present research indicates that egalitarianism, like other intergroup ideologies, may relate to intergroup attitudes in different ways (Guimond, 2010). Whereas past studies have for instance shown that conformity to egalitarian norms only appears when ingroup privileges are granted (and not when ingroup privileges are challenged; Falomir-Pichastor, Chatard, Selimbegovic, Konan, \& Mugny, 2013), the present findings show that a threat to ingroup distinctiveness may also moderate the link between ideologies and prejudice (such as the effects of egalitarian values on discrimination only appear when ingroup distinctiveness is granted).

Second, our findings also contribute to research on reactive responses to gender-related identity threats. Gender theorists contend that one of the major elements in the definition of masculinity is heterosexuality (Herek, 1986) and, in line with this contention, research has shown that heterosexual men are strongly motivated to avoid being misclassified as gays (Bosson et al., 2005). Further, it appears that this motivation is related to sexual prejudice (Herek, 1986; Talley \& Bettencourt, 2008), and our findings show how ingroup distinctiveness threats can undermine egalitarianism's potentially positive effect on sexual prejudice. Although egalitarian values are expected 
to increase positive intergroup attitudes, we found that this is not the case when heterosexual men are led to believe they are biologically similar to gay men. It is only when science provides evidence indicating that heterosexuals and homosexuals are biologically different that egalitarianism is actually related to positive attitudes towards homosexuality. However, very little is known about men's awareness of these reactive processes, and further research should investigate whether and when egalitarian men are aware of the inconsistency between their egalitarian values and their heterosexist attitudes.

Finally, these findings are relevant to research on the link between essentialist beliefs and intergroup attitudes. As a matter of fact, and like other essentialist beliefs, biological beliefs may worsen intergroup relations (e.g., Keller, 2005): because they reify categories and increase a group's perceived entitativity (Yzerbyt, Rocher, \& Schadron, 1997), biological beliefs may naturalize, justify, and even increase existing intergroup inequalities across a wide range of domains (Shostak, Freese, Link, \& Phelan, 2009). Beliefs in biological differences may also reduce prejudice because they increase the perception that a stigmatized behavior is not under individuals' control and responsibility (e.g., Haider-Markel \& Joslyn, 2008). Lastly, biological beliefs may also reflect or justify pre-existing attitudes and group-based motivations (e.g., Falomir-Pichastor \& Hegarty, 2014; Hegarty, 2002; Morton \& Postmes, 2009).

Our results provide useful insights into the complex link between biological beliefs and prejudice in several ways. First, despite that biological beliefs about sexual identity are often related to immutability beliefs (e.g., Haslam \& Levy, 2006; Hegarty, 2002), the present findings suggest that these beliefs may be consistent with both immutability and distinctiveness beliefs (see also Falomir-Pichastor \& Hegarty, 2014). Indeed, our experimental induction directly framed the biological theory of sexual identity in terms of perceived intergroup differences. Results showed no influence of this manipulation on the perception that sexual orientation is under individual control, and this perception was not correlated to sexual prejudice. Therefore, these findings suggest that the effect of our manipulation of the biological theory on sexual prejudice cannot be explained in terms of increased immutability beliefs.

Second, past research has also shown that distinctiveness beliefs are in general related to prejudice towards homosexuality and gay men (Haslam \& Levy, 2006; Hegarty, 2002). However, our studies show that the relationship between beliefs in intergroup biological differences and sexual prejudice can vary as a function of individual and contextual factors. As a matter of fact, the present research showed a beneficial effect of distinctiveness beliefs, such as some people found it easier to apply their egalitarian values to biologically dissimilar gay men rather than to biologically similar ones. This finding is consistent with an alternative understanding of biological and distinctiveness beliefs, according to which they may also accomplish a boundary reinforcement (defensive) function when discrete and clear-cut intergroup differences are needed (Falomir-Pichastor \& Hegarty, 2014; Falomir-Pichastor \& Mugny, 2009; see also Haslam \& Levy, 2006). In this respect, they should not only be considered as beliefs that contribute to reducing sexual prejudice per se, but also as beliefs that offer the possibility of satisfying important intergroup differentiation needs, thereby increasing the influence of egalitarian values on intergroup attitudes. Further research is needed to examine which factors moderate the specific functions that biological beliefs accomplish for different people in different contexts, and how these functions determine the way these beliefs relate to intergroup attitudes.

Despite the relevance of the present findings, the studies described also present a number of limitations that should be addressed in future research. First, it is difficult to assess reactive distinctiveness processes directly, because people may be unaware of distinctiveness motives or may be motivated to hide them. To illustrate their existence, we used a quasiexperimental approach in which we manipulated the perception of intergroup differences, whilst dependent measures did not include a measure of our participant's intrinsic distinctiveness motive. Thus, our results still provide only indirect support for the contention according to which such distinctiveness motives are initially high and satisfied by our manipulation. Therefore, further research using alternative methods is needed to provide a more cogent test of this hypothesis. For instance, future studies should examine whether the predicted pattern of findings varies as a function of population gender (heterosexual men versus heterosexual women), target group (gays versus lesbians), or individual differences in the extent to which men endorse masculinity norms or are easily threatened by intergroup similarity. Further research is also welcome to examine the specificity of egalitarian values as compared to other values, be they related in general to positive (e.g., tolerance) or negative (e.g., power or security) intergroup attitudes.

Another potential limitation regards the role of the pre-existing beliefs about sexual orientation's biological bases. Indeed, perceived biological similarity between heterosexual and gay men was high in the control condition, and similar to that observed in the biological similarity condition (Study 1). This result may challenge our understanding of the predicted 
pattern of findings at least in two ways. First, we cannot definitely affirm that the predicted reactive distinctiveness is, as we assumed, related to the very definition of masculinity (i.e., as opposed to femininity and homosexuality), rather than to men's strong perception of intergroup similarity. Second, one could also argue that the present results could result from the greater discrepancy between participants' pre-existing beliefs (i.e., the perception of biological intergroup similarities) and the biological differences condition, as compared to the biological similarities condition. As a consequence, strong egalitarians would have reduced their prejudice in the condition in which the manipulation challenged their existing knowledge of homosexuality. Future research is needed in order to disentangle these alternative explanations.

Finally, the results of these two studies gain in validity due to the fact that the observed pattern of findings is consistent across two different countries. Indeed, even if past research has shown that culture influences both self-enhancement motives and prejudice expression (e.g., Markus \& Kitayama, 1991), we have shown here that the investigated reactive distinctiveness process does not vary across two samples of university students from Switzerland and Ecuador. Furthermore, this consistent pattern of findings was observed despite differences between these two samples on participants' level of sexual prejudice and perceived biological determinism, thereby providing additional support to the idea that the examined process is consistent across these two countries. That said, cultural variations in these reactive distinctiveness processes might be observed, for instance, in comparison with countries in which masculinity is not so strongly tied to heterosexuality, or even in countries in which masculinity is not so much of an important part of men's self-concept. Further research is needed in this respect.

\section{References}

Bahns A., \& Crandall C. S. (2013). The opposite of backlash: High-SDO people show enhanced tolerance when gay people pose little threat. European Journal of Social Psychology, 43, 286-291. http://dx.doi.org/10.1002/ ejsp.1947

Bem S. L. (1993). The lenses of gender: Transforming the debate on sexual inequality. New Haven, CT: Yale University Press.

Biernat M., \& Vescio T. K. (1996). Values and prejudice. In C. S. Crandall \& M. Schaller (Eds.), Social psychology of prejudice: Historical and contemporary issues (pp. 191-216). Lawrence, KS: Lewinian press.

Bosson J. K., Prewitt-Freilino J. L., \& Taylor J. N. (2005). Role rigidity: A problem of identity misclassification. Journal of Personality and Social Psychology, 89, 552-565. http:/ /dx.doi.org/10.1037/0022-3514.89.4.552
Brewer M. B. (1991). The social self: On being the same and different at the same time. Personality and Social Psychology Bulletin, 17, 475-482. http:/ /dx.doi.org/ $10.1177 / 0146167291175001$

Burn S. M. (2000). Heterosexuals' use of "fag" and "queer" to deride one another: A contributor to heterosexism and stigma. Journal of Homosexuality, 40, 1-11. http:/ / dx.doi. org/10.1300/J082v40n02_01

Carnaghi A., Maass A., \& Fasoli F. (2011). Enhancing masculinity by slandering homosexuals: The role of homophobic epithets in heterosexual gender identity. Personality Social Psychology Bulletin, 37, 1655-1665. http:// dx.doi.org/10.1177/0146167211424167

Correll J., Park B., \& Smith J. A. (2008). Colorblind and multicultural prejudice reduction strategies in highconflict situations. Group Processes \& Intergroup Relations, 11, 471-491. http:/ /dx.doi.org/10.1177/1368430208095401

Crandall C. S., \& Eshleman A. (2003). A justificationsuppression model of the expression and experience of prejudice. Psychological Bulletin, 129, 414-446. http:/ /dx. doi.org/10.1037/0033-2909.129.3.414

Crandall C. S., Eshleman A., \& O' Brien L. (2002). Social norms and the expression and suppression of prejudice: The struggle for internalization. Journal of Personality and Social Psychology, 82, 359-378. http:/ /dx.doi.org/10.1037/ 0022-3514.82.3.359

Davidov E., Schmidt P., \& Schwartz S. H. (2008). Bringing values back in: The adequacy of the European Social Survey to measure values in 20 countries. Public Opinion Quarterly, 72, 420-445. http://dx.doi.org/10.1093/poq/ nfn035

Feather N. T. (2005). Values, religion, and motivation. In M. L. Maehr, \& S. A. Karabenick (Eds.), Advances in motivation and achievement (Vol. 14, pp. 35-73). Amsterdam, The Netherlands: Elsevier.

Feather N. T., \& McKee I. R. (2008). Values and prejudice: Predictors of attitudes towards Australian Aborigines. Australian Journal of Psychology, 60, 80-90. http:/ /dx.doi. org $/ 10.1080 / 00049530701449513$

Falomir-Pichastor J. M., Chatard A., Selimbegovic L., Konan P. N. D., \& Mugny G. (2013). Conformity and counter-conformity to anti-discrimination norms: The moderating effect of attitudes towards foreigners and perceived ingroup threat. Journal of Applied Social Psychology, 43, E206-E215. http://dx.doi.org/10.1111/ jasp.12024

Falomir-Pichastor J. M., \& Hegarty P. (2014). Maintaining distinctions under threat: Heterosexual men endorse the biological theory of sexuality when equality is the norm. 53, 731-751 British Journal of Social Psychology. http:/ /dx. doi.org/10.1111/bjso.12051

Falomir-Pichastor J. M., Martinez C., \& Paterna C. (2010). Gender role, perceived similarity, and sexual prejudice against gay men. The Spanish Journal of Psychology, 13, 841-848. http:/ /dx.doi.org/10.1017/S1138741600002493

Falomir-Pichastor J. M., \& Mugny G. (2009). “I'm not gay...I'm a real man!": Heterosexual men's gender self-esteem and sexual prejudice. Personality and Social Psychology Bulletin, 35, 1233-1243. http:/ / dx.doi. org $/ 10.1177 / 0146167209338072$ 
Gabarrot F., Falomir-Pichastor J. M., \& Mugny G. (2009). Being similar versus being equal: Intergroup similarity moderates the influence of in-group norms on discrimination and prejudice. British Journal of Social Psychology, 48, 253-273. http:/ /dx.doi.org/10.1348/014466608X342943

Gaertner S. L., Mann J., Murrell A., \& Dovidio J. F. (1989). Reducing intergroup bias: The benefits of recategorization. Journal of Personality and Social Psychology, 57, 239-249. http:/ / dx.doi.org/10.1037/0022-3514.57.2.239

Glick P., Gangl C., Gibb S., Klumpner S., \& Weinberg E. (2007). Defensive reactions to masculinity threat: More negative affect toward effeminate (but not masculine) gay men. Sex Roles, 57, 55-59. http:/ /dx.doi.org/10.1007/ s11199-007-9195-3

Guimond S. (2010). Psychologie sociale: Perspective multiculturelle. Wavre, Belgian: Editions Mardaga.

Haider-Markel D. P., \& Joslyn M. R. (2008). Understanding beliefs about the origins of homosexuality and subsequent support for gay rights: An empirical test of attribution theory. Public Opinion Quarterly, 72, 291-310. http:/ / dx.doi.org/10.1093/poq/nfn015

Haslam N., \& Levy S. R. (2006). Essentialist beliefs about homosexuality: Structure and implications for prejudice. Personality and Social Psychology Bulletin, 32, 471-485. http:/ /dx.doi.org/10.1177/0146167205276516

Hegarty P. (2002). 'It's not a choice, it's the way we're built': Symbolic beliefs about sexual orientation in the US and Britain. Journal of Community and Applied Social Psychology, 12, 153-166. http:/ /dx.doi.org/10.1002/casp.669

Herek G. M. (1986). On heterosexual masculinity: Some psychical consequences of the social construction of gender and sexuality. American Behavioral Scientist, 29, 563-577. http:/ /dx.doi.org/10.1177/000276486029005005

Hofstede G., Hofstede G. J., \& Minkov M. (2010). Cultures and organizations: Software of the mind ( $3^{\text {rd }}$ Ed.). New York, NY: McGraw-Hill.

Hornsey M. J., \& Hogg M. A. (2000). Assimilation and diversity: An integrative model of subgroup relations. Personality and Social Psychology Review, 4, 143-156. http:/ / dx.doi.org/10.1207/S15327957PSPR0402_03

Jetten J., \& Spears R. (2003). The divisive potential of differences and similarities: The role of intergroup distinctiveness in intergroup differentiation. European Review of Social Psychology, 14, 203-241. http:/ / dx.doi. org/10.1080/10463280340000063

Keiller S. W. (2010). Masculine norms as correlates of heterosexual men's attitudes toward gay men and lesbian women. Psychology of Men \& Masculinity, 11, 38-52. http:/ / dx.doi.org/10.1037/a0017540

Keller J. (2005). In genes we trust: The biological component of psychological essentialism and its relationship to mechanisms of motivated social cognition. Journal of Personality and Social Psychology, 88, 686-702. http://dx. doi.org/10.1037/0022-3514.88.4.686

Markus H. R., \& Kitayama S. (1991). Culture and the self: Implications for cognition, emotion and motivation.
Psychological Review, 98, 224-253. http:/ /dx.doi. org/10.1037/0033-295X.98.2.224

Morton T. A., \& Postmes T. (2009). When differences become essential: Minority essentialism in response to majority treatment. Personality and Social Psychology Bulletin, 35, 656-668. http:/ /dx.doi.org/10.1177/ 0146167208331254

Mugny G., Sanchez-Mazas M., Roux P, \& Pérez J. A. (1991). Independence and interdependence of group judgments: Xenophobia and minority influence. European Journal of Social Psychology, 21, 213-223. http://dx.doi.org/10.1002/ ejsp.2420210304

Rokeach M. (1973). The nature of human values. New York, NY: Free Press.

Sanchez-Mazas M., Roux P., \& Mugny G. (1994). When the outgroup becomes ingroup and when the ingroup becomes outgroup: Xenophobia and social categorization in a resource allocation task. European Journal of Social Psychology, 24, 417-423. http://dx.doi.org/10.1002/ ejsp. 2420240309

Schwartz S. H. (1992). Universals in the content and structure of values: Theoretical advances and empirical tests in 20 countries. In M. P. Zanna (Ed.), Advances in experimental social psychology (Vol. 25, pp. 1-65). Orlando, FL: Academic Press.

Shostak S., Freese J., Link B. G., \& Phelan J. C. (2009) The politics of the gene: Social status and beliefs about genetics for individual outcomes. Social Psychology Quarterly, 72, 77-93. http:/ / dx.doi.org/10.1177/019027250907200107

Tajfel H., \& Turner J. C. (1986). The social identity theory of intergroup behavior. In S. Worchel, \& W. G. Austin (Eds.), Psychology of Intergroup Relations (pp. 7-24). Chicago, IL: Nelson-Hall.

Talley A. E., \& Bettencourt B. A. (2008). Evaluations and aggression directed at a gay male target: The role of threat and antigay prejudice. Journal of Applied Social Psychology, 38, 647-683. http://dx.doi.org/10.1111/j.1559-1816. 2007.00321.x

Theodore P. S., \& Basow S. A. (2000). Heterosexual masculinity and homophobia: A reaction to the self? Journal of Homosexuality, 40, 31-48. http:/ /dx.doi. org/10.1300/J082v40n02_03

Whitley B. E., Jr. (2001). Gender-role variables and attitudes toward homosexuality. Sex Roles, 691-721. http:/ / dx.doi. org/10.1023/A:1015640318045

Wolsko C., Park B., Judd C. M., \& Wittenbrink B. (2000). Framing interethnic ideology: Effects of multicultural and color-blind perspectives on judgments of groups and individuals. Journal of Personality and Social Psychology, 78, 635-654. http://dx.doi.org/10.1037// 0022-3514.78.4.635

Yzerbyt V., Rocher S., \& Schadron G. (1997). Stereotypes as explanations: A subjective essentialistic view of group perception. In R. Spears, P. J. Oakes, N. Ellemers, \& S. A. Haslam (Eds.), The social psychology of stereotyping and group life (pp. 20-50). Malden, MA: Blackwell. 